\title{
Coping with domestic violence: women's voices in Bangladesh
}

\section{Coping with domestic violence}

\author{
Marc van der Putten and Amee Nur-E-Jannat \\ Faculty of Public Health, Thammasat University-Rangsit Campus, \\ Khlong Luang, Thailand
}

\begin{abstract}
Purpose - This paper aims offer a benchmark by providing an account of women's experiences with domestic violence in Bangladesh and develops illustrations on coping with abuse.

Design/methodology/approach - A case study design was adopted, applying an emic perspective in employing a qualitative research approach to explore and describe women's experiences with and perceptions about domestic violence and their ways of coping in Sherpur District, Bangladesh. In total 25 recently married women participants were purposively sampled by snowballing. In-depth interview data facilitated a latent thematic content analysis.

Findings - The findings indicate that women adopt a range of responses to domestic violence. Two key aspects of coping surfaced in the narratives: (1) emotion-driven and (2) problem-driven approaches to abusive situations. Findings point to a range of research issues that require further study such as domestic violence and taboo; somatization; structural gender inequalities; male perpetrators; family dynamics and the intersections of these issues and contexts.

Originality/value - A more proactive way of coping resulted in resilience amidst an abusive environment, whereas passive ways of coping led to a life in distress. It is important however, to understand ways of coping as a continuum rather than a dichotomy.
\end{abstract}

Keywords Domestic violence, Women, Coping, Bangladesh

Paper type Research paper

\section{Introduction}

Domestic violence makes women in families and societies captive, whether through physical, financial, psychological or social abuse or any combination of these. Although having a life free of violence is a basic human right, $30 \%$ of women globally have experienced violence at home. In South Asia, the percentage is $50 \%$, with Bangladesh showing a staggering prevalence of $87 \%$ of women facing domestic violence despite existing protective policies and laws in place [1]. Women experiencing domestic violence face both short and long-term physical, psychological, and social consequences impacting their health and well-being. The precursors and effects of domestic violence against women in South Asian societies are well-documented [2-12].

The literature offers a variety of theories concerning domestic violence against women. In the context of this study, the social learning theory, the family systems theory and the feminist theory were informative. The "social learning theory" presumes that abusive or violent behavior is learned throughout childhood experience; the "family systems theory" looks at the functioning and interactions of the entire extended family who tend to blame the victim; and the "feminist theory" argues that a patriarchal society supports male power, female submission, and inequities that lead to violence against women [13].

(C) Marc van der Putten and Amee Nur-E-Jannat. Published in the Journal of Health Research. Published by Emerald Publishing Limited. This article is published under the Creative Commons Attribution (CC BY 4.0) licence. Anyone may reproduce, distribute, translate and create derivative works of this article (for both commercial and non-commercial purposes), subject to full attribution to the original publication and authors. The full terms of this licence may be seen at http://creativecommons.org/licences/by/4.0/ legalcode

This work was supported by a thesis research grant from Thammasat University, Thailand.

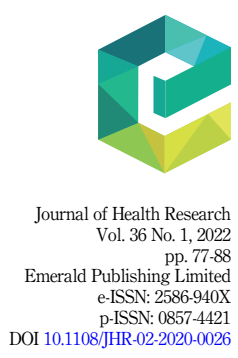

Received 5 February 2020 Revised 30 March 2020 Accepted 4 May 2020

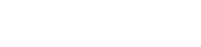


JHR

36,1

78

From a socio-cultural perspective, deep-rooted patriarchy in Bangladesh places women as subservient under male domination and is commonly reflected through violence against them. Domestic violence is attributed to the husband's and in-laws' desire to control behavior and reassert their authority when challenged. Moreover, violence against women is often considered legitimate by the community [3].

The constitution of Bangladesh guarantees equal rights for men and women in all spheres of state and public life. Bangladesh also signed the "Convention for the Elimination of All Forms of Discrimination Against Women" in 1984. The dowry was banned by the 1980 "Dowry Prohibition Act", the 2000 "Nari-O-ShishuNirjatan Daman Ain (law against domestic violence against women and children)", the 2000 "Acid Crime Prevention Act", the 2010 "Family Violence Prevention and Protection Act" and the 2011 "National Women Policy" were passed to protect women [5]. However, the common practice to this day of abusing and harming women in Bangladesh does not reflect a commitment to enforce the protection of women's rights.

Notwithstanding deep-rooted abuse, women in Bangladesh often seem to cope despite the negative impact of the abuse they have experienced. Studies adopting an emic perspective of victimized women in dominant patriarchal South Asian societies are scarce. In the context of various conceptualizations on domestic violence against women, the question was, where is the voice of women in this debate? It was unclear how Bangladeshi women coped with domestic violence and this was deemed a void worth exploring.

Coping strategies take various forms. The literature tends to divide these forms into proactive and reactive pairs [14]; problem-focused coping and avoidance coping [15] and passive coping versus active coping [16]. In some studies, proactive coping was associated with a lower level of distress and was considered preferable over passive coping [17]. Other studies focused on areas where women cannot effectively resist violence while living in a dominant patriarchal context and where violence against women is embedded in the societal fabric, a carefully tailored combination of active and passive strategies is considered to be more effective in mitigating violence and avoiding counterproductive consequences of challenging the situation [18,19]. In studies involving older women who experienced a lifetime of domestic violence but made a commitment to keep the family intact, women reported employing both emotion-driven and problem-driven strategies that evolved into a "philosophy of survival" [20]. However, other studies that examined coping mechanisms among women in rural versus urban settings found that problem-focused coping became more action-oriented by seeking help due to service accessibility, community and sociocultural factors within the urban environment [21].

Given the prevalence of domestic violence in Bangladesh, it is important to understand how young married women cope with domestic violence as the findings could inform community-based initiatives in the Bangladeshi context. This paper provides an account of the impact of abuse on recently married women in Bangladesh and examines women's coping mechanisms to understand how women's interpretations of the abusive situation influenced their decisions to deal with abuse. The findings aimed to provide a benchmark in understanding women's coping strategies relating to abusive domestic situations and offers in sights in to potential pathways to respond to young married women's needs.

\section{Methodology}

This study adopted a case study design [22], applying an emic perspective in employing a qualitative research approach [23] to explore and describe women's experiences with and perceptions of domestic violence and their ways of coping. Because of its focus on the family context, the diversity of interactions, and the exploration of a social phenomenon, a case study approach was deemed most suitable [24,25]. 
Women residing in Sherpur District, Bangladesh participated in this study. This site was selected because (1) the Sherpur community is comparable to other districts in the country; and (2) the researcher grew-up in Sherpur, was known by villagers, and was well-acquainted with the socio-cultural context, which enabled access to women. In addition, (3) the researcher spoke the local dialect which helped establish rapport with participants. Given the taboo surrounding domestic violence against women, identification of potential participants became a challenge, hence snowball sampling was employed. The median age of marriage for women in Bangladesh was 17.3 years [26], and previous studies consistently indicated that women's relative youth is an important risk factor for violence within marriage [27]. Based on these factors, this study included married women between 18 and 25 years of age who experienced domestic violence but excluded women who self-reported suffering from a mental disorder. The first participants were identified by development workers in the locality. To minimize sampling bias, the first participants came from multiple villages for exponential discriminative snowballing. Sampling continued until saturation was reached.

At marriage, young women move in with their in-laws. On joining their in-laws, newlywed women are positioned at the bottom of the family hierarchy, while the husband often remains loyal to his family, making his wife susceptible to abuse. Only over time when sistersin-law move out and in-law parents grow older and become more dependent do married women gain status within the family.

In-depth interviews with 25 women who experienced domestic violence were facilitated by a semi-structured questionnaire against the background of family systems and feminist theory, and were conducted in Bengali between October 2018 and January 2019. The sampled women in Sherpur District were invited to participate in a study about domestic violence. Before obtaining informed consent, the researcher explained the purpose of the project, answered participants' questions, and requested permission to audio-record the interview. Interviews were conducted at times and places convenient to the participants while ensuring privacy. Interviews were audio-recorded, transcribed verbatim, translated into English, and a random sample was independently back-translated into Bengali. The data included jotted notes, interview transcripts, and the researcher's reflective diary. Personal identifiers were removed and replaced with interview codes to ensure confidentiality.

An inductive thematic latent content analysis was applied throughout the data collection stage. This analysis, based on a constructionist perspective, assisted in the development of a thematic map [28]. The thematic analysis provided a flexible approach that could be modified for the needs of the study [29]. Interview transcripts were coded, and coded data served as the basis to create categories and themes [30]. While thematic analysis is flexible, this flexibility can lead to inconsistencies when developing themes during the analysis. Therefore, consistency was promoted by employing the family systems and feminist and coping theories to underpin the study's claims [31].

All through the coding stage, categories were identified and developed using the following techniques: (1) verbatim analysis of the data and generation of categories, and (2) comparison between individual cases and categories that were grouped into themes based on similar incidents [32]. Throughout the analysis process, outcomes were triangulated across participants to identify cross-validation and or discrepancy.

\section{Ethical statement}

This study was approved by the Human Ethical Review Committee \#3, Thammasat University, Thailand on October 4, 2018. The authors had no conflict of interest to report.
Coping with domestic violence 
JHR

36,1

\section{Results}

Participants' profiles

A total of 25 women participated in this study, with the majority between 20 and 25 years of age. All participants were members of the Muslim community. A total of 10 participants lived in rural areas and 15 lived in suburban areas. All women were married and 22 of them had children. All participants were literate, among them, 4 were university graduates, 19 completed secondary school, and 2 had no formal education. In terms of occupation, 2 participants were government employees while 23 women were housewives. Among the housewives, 11 reported contributing to the family income by sewing clothes, engaging in animal husbandry responsibilities or by working at other people's houses during harvesting time.

\section{Participants' views on domestic violence}

Participants believed that men were more important to society as they generated an income. On the contrary, when women generated income they were not treated as equally important. Respondents explained that there was very little flexibility for women. Commonly, their inlaws and husbands controlled almost every aspect of their domestic life. The women described that verbal and physical abuse was considered normal and socially acceptable.

Scolding, shouting (at the wife) for very small reasons. Using very bad language. Not only my husband would do it, but also my mother-in-law, father-in-law, sister-in-law, and brother-in-law.

My mother-in-law would keep on complaining to my husband until he (husband) beat me up. He had to beat me up, or at least shout at me for my presumed mistakes to make his mother happy. Once I tried to defend myself and he kicked me because I spoke, I fell onto the ground.

\section{Forms of domestic violence experienced}

All participants stated that they felt neglected. Most women said their contribution to the family was overlooked, and that their concerns about the family were often considered as "overthinking" and "illogical". They claimed that they were not valued by their respective husbands and their in-laws. As one woman observed:

Being a woman, we commonly experience physical and psychological tortures. Neglect about one's needs too. Neglect and maltreatment are very common things here. So common that no one will take it seriously.

If women were not able to give birth to a male child, or unable to have children, interviewees explained that it would be highly likely that their husband would divorce them or take a second wife. If women gave birth to several girls, they were threatened with divorce by their husbands and in-laws. In some cases, if their own health was compromised and required medical care, they were divorced.

My mother-in-law wanted my husband to marry again because I had 3 daughters and no son. My parents were poor. They took dowry from my parents, now if I was divorced and sent back, how could my parents feed me and my daughters? Luckily Allah gave me a son and now things are better.

The most common form of maltreatment reported was verbal abuse such as shouting, calling names and using offensive language. This included judgments, comparing them with other women in the neighborhood, accusing them of stealing or falsely blaming them of cheating on their husbands. Many complained about their husbands' ill-temper and the abusive behavior of their in-laws. As one participant said:

My husband and the entire in-law family scold and shout at me for futilities. They always find fault with my work, no matter how dedicated I am when I worked, no matter how tired I was after work. Using rude language in commenting on me and my parents. 
Physical abuse such as slapping could be triggered by small incidents such as insufficient salt in the food. Common forms of physical abuse reported by interviewees included pushing, slapping, beating, kicking, pulling hair, denying food or throwing them out of the house.

Husbands or fathers-in-law often refused to bear the healthcare expenses of their wives or daughters-in-law by downplaying the need for treatment or postponing care. Women were often blamed for their sickness and were sent back to their parents' house for treatment, so the husband's family did not have to pay for a doctor's consultation and treatment:

If I was sick, I asked them to take me to the hospital, but they never took me there. I felt so neglected the first few times when I sought their sympathy and help. Do you know what my father-in-law said? He said 'what is this? how can young people be sick? She is just pretending'.

Some respondents recalled incidents of severe violence leading to injuries and death among their acquaintances, for example, two women were burnt to death, another woman's arm was cut off and other women had acid thrown onto their faces. Each of these cases were of dowry related violence. More common injuries included bruises, hematoma, cuts and sporadic fractures.

\section{Powerlessness}

Women wanted respect, they wanted to be valued and treated as one of the family by their in-laws. When asked what their dreams were, each of them replied that they wanted to be loved back by their husbands and in-laws and hoped to achieve this in the future when their children grew up.

I just wish that they loved me. I need nothing else. I am not like any other woman. Others want wealth, luxury, things, but for me, I don't need any of those, I just need my people to love me, and to appreciate my love for them.

\section{Psychological distress}

Several women claimed that not having hope made coping difficult, and in some cases, impossible. They also explained that society viewed women who were unable to cope with oppression as failures. Women seem to be caught-up between social norms and expectations and their personal needs and aspirations. As explained by one of the participants:

A woman has to know how to hope and dream; if not, she won't be able to survive in her marriage and those women are not good women, you know? Women are born to compromise. If they don't want to comply with this expectation, they cannot remain married and they will bring shame to their parents.

\section{Resilience}

Several strategies were used by participants, for example, patience and hope were commonly used words when they were explaining how they adjusted to an abusive environment. When they described themselves as being patient, they did not mean that being patient was their only choice, but that the alternative, for example being confrontational, was deemed worse than an abusive environment. As women settled into living with their in-laws and married life, they learned to accept the situation and gain insights into and understanding of the in-law family's dynamics and learned to foresee triggers of abuse. This helped them to avoid troublesome situations and eventually, the situation gradually became easier for them.

I used to speak up in the beginning, but I learned that I did not gain from this. Speaking up never improved anything, it only made things worse. So, I learned how to behave more strategically. Now, I sometimes lead my husband and the other people here to do something that I want, without them understanding that I am being diplomatic. 
JHR

36,1

Those women who experienced violence from their husbands found it to be more difficult to deal with than the abuse experienced by other people in the in-law family. In contrast, if women received consolation or help from their husbands, the hardship within the extended family was more bearable. They felt more courageous and able to face the hardship as they had their husbands on their side.

If my husband says something consoling to me, I forget everything that happened. When I have problems with others in the family, my husband supports me most of the time. He noticed how much I suffer. He understands everything that happens to me in that house.

Some participants experienced abuse from both, their husbands and their in-laws. These women used patience to survive their marriage. Eventually, their families became dependent on them and considered them as an indispensable member of the household.

After 4 years of this abusive marriage, now I feel really proud of myself for fighting to survive here in this family. I won, they misbehaved and they lost. I am patient and now they ended up liking me, I can feel in their behavior that they respect me so it's my win.

Some participants used close female relatives to share their sorrows. For example, their parents or siblings, the wife of a brother-in-law or a sister-in-law who was sympathetic to them. Sharing helped them as they received support from this person.

\section{Socio-economic constraints on coping}

Mostly, women's mothers-in-law controlled almost every aspect of their domestic life. Finding fault with their work, accusing them of laziness and accusing them of pretending to be sick to avoid work were common complaints from in-laws. For those women who did have an external job, the responsibility of taking care of household chores was an additional expectation.

Nowadays many women are working outside the home to earn money. Even if they work, they have to take care of all the chores in the house too. No husband will feed them if they don't work.

Participants believed that men were considered more important by society as they worked outside and generated an income. In contrast, women with a job outside the home were not considered equally important and their additional work as housewives was not recognized as work.

Most participants stated that women were given almost no role in decision making within the family, although all of them believed that men and women should engage jointly in decision making. Amongst the wives who had little voice in decision making, they were afraid of being blamed or being ill-treated if they contributed to incorrect decisions.

Women cannot decide for themselves. Even if I am right, still they will say (negative) things, they will make discouraging comments. Whereas, if they came to the same decision, they will be okay with that. If they decide the wrong things, no one will say anything against that. But if it's a woman, then people will say so many things to her.

Even if women made financial contributions to the family, their husbands would control the family finances. If women were obedient to their husbands' decisions on spending family earnings, they believed it was appreciated by the family and by society.

Look at my life, I earn 30 thousand Taka a month, what do you think, in Bangladesh society, it is not a common matter that a wife earns this much money, right? Still, I do not have much to say in my family's decisions.

Women's ways of coping with domestic violence

Because Bangladesh's socio-cultural norms muted women's voices, the majority of women adopted less confrontational ways of coping with abuse. As illustrated in Figure 1, 


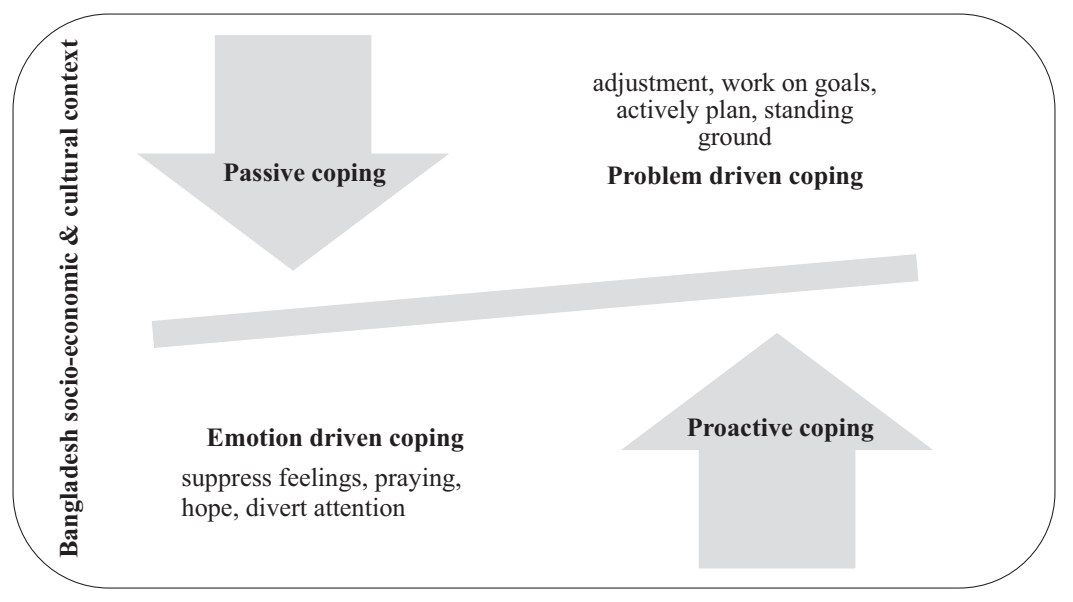

Coping with domestic violence

83

a conceptualization of coping with domestic violence, two main coping strategies surfaced from interview narratives: (1) passive coping (emotion-driven coping) and (2) proactive coping (problem-driven coping); which present a conceptual clarification of themes emerging from the analysis. However, this conceptualization suggests a continuum rather than a binary understanding.

Adopting a continuum allows for a more flexible understanding of ways of coping as women used them with less clear boundaries in the socio-economic and cultural context of Bangladesh.

\section{Passive coping}

Women used various emotion-driven strategies to keep themselves out of trouble. Most participants explained that they kept silent out of fear of provoking their husbands or in-laws. Keeping quiet was a common coping response to abusive incidents. Over time, the women learned to recognize signs of approaching violence and neutralized the situation by pleasing their husbands and/or their in-laws. Often, this meant denial or talking down violent behavior, apologizing or avoidance, and sometimes blaming themselves. Religious beliefs and hope played an important role in participants' recovery from domestic violence.

\section{Proactive coping}

While passive strategies dominated in the women's stories, some women also described using proactive strategies to cope with abuse. Developing resilience was an important quality. Women described their need for courage, strength of will, and persistence to withstand the abuse and not give up. Women described planning for a better future as a way of coping. Strategies included income generation such as seeking employment or taking up animal husbandry; others sought assistance from other family members.

\section{Discussion}

The scope of this study was to explore the experiences and perspectives on domestic violence and ways of coping among recently married women in Sherpur, Bangladesh while confirming that the complexity of domestic violence is embedded in a socio-economic and cultural environment. 
JHR

36,1

The authors acknowledge that snowball sampling is vulnerable to sampling bias, resulting in a homogenous sample, which may affect study findings. However, measures were taken to minimize this disadvantage. Further, while thematic analysis is flexible, this flexibility can lead to inconsistencies when developing themes during the analysis. Consistency was promoted by employing family systems, feminist theories and coping theories to underpin the study's claims [31].

In this study, abuse was experienced by both well-educated and lower-educated women, but the latter reported more experiences with abuse. The majority of well-educated women expressed increased sensibility when reacting to the remarks of their in-laws, which reduced the incidents of abuse. Lower educated women in contrast seemed reactive rather than proactive and as a result, they experienced more abuse, as speaking up for themselves was not tolerated because it undermined the family hierarchy. Kundapur et al. [33] and Sambisa et al. [34] found that similar outcomes. Another factor that could explain lower reporting of violence among higher educated women might be that it reflected the socio-economic status of families which favors gender equity and opens job opportunities that contribute to the family income. Various studies support this proposition [12,35,36]. In contrast, Dalal [37] found that about $80 \%$ of the working women in his study experienced domestic abuse. The question of whether generating family income is seen as undermining the husband's authority and therefore a trigger for abuse is not substantiated in this study. Bates et al. [38] argued that women's economic empowerment often led them to act more assertively in the family, which then increased the likelihood of arguments and violent responses. This view was also supported by Ziaei et al. [12] and Al Mamun et al. [39]. This was then contradicted by Rahman et al. [40] who found that women with lower wealth were more at risk of abuse. Whereas Luciana et al. [41] argued that the economic background of the women's family mattered in terms of how they were treated by their in-laws. The debate continues on the relation between education, income or wealth, and domestic violence, and further studies will be required to explore these interrelations.

The coping strategies that surfaced in the narratives, emotional driven and problemdriven coping, have been explained in several studies [42-44]. However, in this study, several women used a combination of passive and proactive strategies in coping with abuse, which suggests a continuum rather than the conceptual distinction between passive and proactive coping which is supported by other studies [45].

The interviewed women avoided elaborating on aspects of sexual violence. Talking about sex remains a taboo in society and could bring "disgrace to the family". In the Bangladeshi socio-cultural context, women's sexuality is private and controlled. However, a survey study in Bangladesh [46] among recently married women reported that nearly $60 \%$ experienced sexual intimate partner violence such as forced sexual intercourse and engaging in sexual intercourse out of fear.

This study found a variance between urban and rural women's experiences with domestic abuse. The abuse occurred more frequently among rural women, a finding that is supported by other studies [47]. One possible explanation could be that urban women usually live in nuclear families and therefore do not have to face daily interferences from their in-laws. Rural women mostly live in extended families and have to deal with their husband's but also with their in-law's interference. In addition, it can be expected that traditional socio-cultural norms are better preserved in rural settings.

Besides the taboo surrounding women considering divorce, women who had children were more determined to stay with their husbands even if the marriage was abusive. Women feared that leaving their husbands would be disastrous for their children's lives. These findings were supported by other studies [48,49]; whereas others [50] pointed out that having male children offered some degree of protection against domestic violence. 
This study illustrated how women see themselves in the face of abuse and their views on how they coped with abusive environments which are novel for Bangladesh, and therefore, this study offers a benchmark. Further, findings point to a range of domestic violence research issues that require further study such as taboo; somatization; structural gender inequalities; male perpetrators; (in-law) family abuse and the intersections of these issues and contexts.

\section{Conclusion}

Returning to the research question of this study: "How do Bangladeshi women cope with domestic violence?", it can be concluded that some of the women showed a more proactive way of coping which resulted in resilience amidst an abusive environment, whereas others leaned more towards passive ways of coping which led them to live a life in distress. However, it is important not to simplify coping with a dichotomy but to understand ways of coping as a continuum.

Deployment of policy and laws to combat domestic violence remain deficient making effective enforcement slow. Social awareness-raising efforts need to be introduced in which media could play a prominent role. Further study is needed to identify leverage factors for interventions.

Conflict of interest: There is no conflict of interest.

\section{References}

1. World Health Organization [WHO], Department of Reproductive Health and Research, London School of Hygiene and Tropical Medicine, South African Medical Research Council. Global and regional estimates of violence against women: prevalence and health effects of intimate partner violence and non-partner sexual violence. [cited $2020 \mathrm{Jan}$ 30]. Available from: https:/www.who.int/ reproductivehealth/publications/violence/9789241564625/en/.

2. Bajracharya A, Amin S. Microcredit and domestic violence in Bangladesh: an exploration of selection bias influences. Demography. 2013; 50(5): 1819-43. doi: 10.1007/s13524-013-0226-0.

3. Chowdhury MAK, Morium S. Domestic violence against women: a historic and socio-cultural reality in Bangladesh. Eur Sci J. 2015; 11(26): 241-56.

4. Das TK, Bhattacharyya R, Alam MF, Pervin A. Domestic violence in Sylhet, Bangladesh: analysing the experiences of abused women. Soc Change. 2016; 46(1): 106-23. doi: 10.1177/ 0049085715618561.

5. Hossen MA. Measuring gender-based violence: results of the violence against women survey in Bangladesh. [cited 2020 January 30]. Available from: https:/unstats.un.org/unsd/gender/mexico_ nov2014/Session-03-Bangladesh-paper.pdf.

6. Mahapatro M, Gupta R, Gupta V. The risk factor of domestic violence in India. Indian J Community Med. 2012 Jul; 37(3): 153-7. doi: 10.4103/0970-0218.99912.

7. Guruge S, Jayasuriya-Illesinghe V, Gunawardena N, Perera J. Intimate partner violence in Sri Lanka: a scoping review. Ceylon Med J. 2015 Dec; 60(4): 133-8. doi: 10.4038/cmj.v60i4.8100.

8. Hadi A. Patriarchy and gender-based violence in Pakistan. Eur J Soc Sci Educ Res. 2017; 4(4): 297-304.

9. Khan AR. Domestic violence against women in Bangladesh: a review of the literature and the gaps to fill-in by future interventions. Khazar J. Humanit. Soc. Sci. 2015; 18(3): 57-81.

10. Parvin K, Sultana N, Naved RT. Spousal violence against women and help seeking behaviour. In: Naved RT, Amin S, editors. Growing up safe and healthy (SAFE): baseline report on sexual and reproductive health and rights and violence against women and girls in Dhaka slums. Dhaka: ICDDR,B; 2012.
Coping with domestic violence 
JHR

36,1
11. Poudel-Tandukar K, Poudel KC, Yasuoka J, Eto T, Jimba M. Domestic violence against women in Nepal. Lancet. 2008 May; 371(9625): 1664. doi: 10.1016/S0140-6736(08)60723-0.

12. Ziaei S, Frith AL, Ekström EC, Naved RT. Experiencing lifetime domestic violence: associations with mental health and stress among pregnant women in rural Bangladesh: the MINIMat randomized trial. PLoS ONE. 2016; 11(12): e0168103. doi: 10.1371/journal.pone.0168103.

13. McCue ML. Domestic violence: a reference book. 2nd ed. Santa Barbara, Calif: ABC-CLIO; 2008.

14. Mitchell MD, Hargrove GL, Collins MH, Thompson MP, Reddick TL, Kaslow NJ. Coping variables that mediate the relation between intimate partner violence and mental health outcomes among low-income, African American women. J Clin Psychol. 2006 Dec; 62(12): 1503-20. doi: 10.1002/ jclp.20305.

15. Hayati EN, Eriksson M, Hakimi M, Högberg U, Emmelin M. 'Elastic band strategy': women's lived experience of coping with domestic violence in rural Indonesia. Glob. Health Action. 2013 Jan; 6: 1-12. doi: 10.3402/gha.v6i0.18894.

16. Meyer A, Wagner B, Dutton MA. The relationship between battered women's causal attributions for violence and coping efforts. J. Interpers Violence. 2010 May; 25(5): 900-18. doi: 10.1177/ 0886260509336965.

17. Smith PH, Murray CE, Coker AL. The coping window: a contextual understanding of the methods women use to cope with battering. Violence Vict. 2010; 25(1): 18-28. doi: 10.1891/08866708.25.1.18.

18. Abeya SG, Afework MF, Yalew AW. Intimate partner violence against women in west Ethiopia: a qualitative study on attitudes, woman's response, and suggested measures as perceived by community members. Reprod. Health. 2012 Aug; 9: 14. doi: 10.1186/1742-4755-9-14.

19. Zakar R, Zakar MZ, Kramer A. Voices of strength and struggle: women's coping strategies against spousal violence in Pakistan. J. Interpers Violence. 2012 Nov; 27(16): 3268-98. doi: 10.1177/ 0886260512441257.

20. Zink T, Jacobson CJ Jr, Pabst S, Regan S, Fisher BS. A lifetime of intimate partner violence: coping strategies of older women. J. Interpers Violence. 2006 May; 21(5): 634-51. doi: 10.1177/ 0886260506286878 .

21. Shannon L, Logan TK, Cole J, Medley K. Help-seeking and coping strategies for intimate partner violence in rural and urban women. Violence Vict. 2006 Apr; 21(2): 167-81. doi: 10.1891/vivi.21. 2.167 .

22. Yin RK. Case study research: design and methods. 4th ed. London: Sage; 2009.

23. Given LM. The sage encyclopedia of qualitative research methods. London: Sage; 2008. 1-2.

24. Creswell JW, Poth CN. Qualitative inquiry and research design: choosing among five approaches. London: SAGE; 2018.

25. Ridder HG. The theory contribution of case study research designs. Business Research. 2017; 10(2): 281-305. doi: 10.1007/s40685-017-0045-z.

26. National Institute of Population Research and Training [NIPORT]. Bangladesh demographic and health survey 2017-2018: key indicators. Dhaka: NIPORT; 2019.

27. Naved RT, Persson LA. Factors associated with spousal physical violence against women in Bangladesh. Stud Fam Plann. 2005 Dec; 36(4): 289-300. doi: 10.1111/j.1728-4465.2005.00071.x.

28. Vaismoradi M, Turunen H, Bondas T. Content analysis and thematic analysis: implications for conducting a qualitative descriptive study. Nurs Health Sci. 2013 Sep; 15(3): 398-405. doi: 10.1111/ nhs. 12048 .

29. Braun V, Clarke V. Using thematic analysis in psychology. Qual Res Psychol. 2006; 3(2): 77-101. doi: 10.1191/1478088706qp063oa.

30. Vaismoradi M, Jones J, Turunen H, Snelgrove S. Theme development in qualitative content analysis and thematic analysis. J Nurs Educ Pract. 2016; 6(5). doi: 10.5430/jnep.v6n5p100. 
31. Nowell LS, Norris JM, White DE, Moules NJ. Thematic analysis: striving to meet the trustworthiness criteria. Int J Qual Methods. 2017; 16: 1-13. doi: 10.1177/1609406917733847.

32. Miles MB, Huberman AM. Qualitative data analysis: an expanded sourcebook. 2nd ed. London: SAGE; 1994.

33. Kundapur R, Shetty SM, Kempaller VJ, Kumar A, Anurupa M. Violence against educated women by intimate partners in urban Karnataka, India. Indian J Community Med. 2017 Jul-Sep; 42(3): 147-50. doi: 10.4103/ijcm.IJCM_41_16.

34. Sambisa W, Angeles G, Lance PM, Naved RT, Curtis SL. Physical and sexual abuse of wives in urban Bangladesh: husbands' reports. Stud Fam Plann. 2010 Sep; 41(3): 165-78. doi: 10.1111/j.17284465.2010.00241.x.

35. Hadi A. Women's productive role and marital violence in Bangladesh. J Fam Violence. 2005; 20(3): 181-9. doi: 10.1007/s10896-005-3654-9.

36. Koenig MA, Ahmed S, Hossain MB, Mozumder AK. Women's status and domestic violence in rural Bangladesh: individual- and community-level effects. Demography. 2003 May; 40(2): 269-88. doi: 10.1353/dem.2003.0014.

37. Dalal K. Does economic empowerment protect women from intimate partner violence? J Inj Violence Res. 2011; 3(1): 35-44. doi: 10.5249/jivr.v3i1.76.

38. Bates LM, Schuler SR, Islam F, Islam K. Socioeconomic factors and processes associated with domestic violence in rural Bangladesh. Int Fam Plan Perspect. 2004 Dec; 30(4): 190-9. doi: 10.1363/ 3019004

39. Al Mamun M, Parvin K, Yu M, Wan J, Willan S, Gibbs A, Jewkes R, Naved RT. The her respect intervention to address violence against female garment workers in Bangladesh: study protocol for a quasi-experimental trial. BMC Publ. Health. 2018 Apr; 18(1): 512-28. doi: 10.1186/s12889-018$5442-5$.

40. Rahman M, Hoque MA, Mostofa MG, Makinoda S. Association between adolescent marriage and intimate partner violence: a study of young adult women in Bangladesh. Asia Pac J Public Health. 2014 Mar; 26(2): 160-8. doi: 10.1177/1010539511423301.

41. Luciana S, Amin S, Huq L, Chowdury K. Does dowry improve life for brides? A test of the bequest theory of dowry in rural Bangladesh. Policy Research Division Working Paper no. 195. New York: Population Council; 2004.

42. Bahrami M, Shokrollahi P, Kohan S, Momeni G, Rivaz M. Reaction to and coping with domestic violence by Iranian women victims: a qualitative approach. Glob J Health Sci. 2015 Nov; 8(7): 100-9. doi: 10.5539/gjhs.v8n7p100.

43. Girdano D, Dusek DE, Everly GR Jr. Controlling stress and tension. 9th ed. London: Pearson; 2012.

44. Waldrop AE, Resick PA. Coping among adult female victims of domestic violence. J Fam Violence. 2004; 19(5): 291-302. doi: 10.1023/B:JOFV.0000042079.91846.68.

45. Ben-Ari A, Winstok Z, Eisikovits Z. Choice within entrapment and entrapment within choice: the challenge facing battered women who stay. Fam Soc. 2003; 84(4): 539-46. doi: 10.1606/1044-3894.132.

46. Esie P, Osypuk TL, Schuler SR, Bates LM. Intimate partner violence and depression in rural Bangladesh: accounting for violence severity in a high prevalence setting. SSM Popul Health. 2019 Apr; 7: 100368. doi: 10.1016/j.ssmph.2019.100368.

47. Garcia-Moreno C, Jansen HAFM, Ellsberg M, Heise L, Watts C. WHO multi-country study on women's health and domestic violence against women: initial results on prevalence, health outcomes and women's responses. Geneva: WHO; 2005.

48. Bhuiya A, Sharmin T, Hanifi SM. Nature of domestic violence against women in a rural area of Bangladesh: implication for preventive interventions. J Health PopulNutr. 2003 Mar; 21(1): 48-54.

49. Naved RT, Azim S, Bhuiya A, Persson LA. Physical violence by husbands: magnitude, disclosure and help-seeking behavior of women in Bangladesh. Soc Sci Med. 2006 Jun; 62(12): 2917-29. doi: 10. 1016/j.socscimed.2005.12.001.

Coping with domestic violence 
50. Sharma I. Violence against women: where are the solutions? Indian J Psychiatry. 2015 Apr-Jun; 57(2): 131-9. doi: 10.4103/0019-5545.158133.

\section{Corresponding author}

Marc van der Putten can be contacted at: marc.vdp@fph.tu.ac.th 